\title{
Copyright Literacy in the UK: a survey of librarians and other cultural heritage sector professionals
}

\author{
Chris Morrison, Jane Secker
}

\begin{abstract}
Based on a survey of UK library and information professionals and those who work in the cultural heritage sector, carried out in December 2014, this research sought to examine the levels of copyright 'literacy'. The survey aimed to obtain responses from all sectors, however most responses were received from academic libraries. The research examined their knowledge of national and international copyright issues as well as copyright policies at an institutional level. The survey also explored the need for copyright education for new and existing professionals and suggested topics for inclusion in training activities. The findings suggest that levels of knowledge amongst UK professionals are higher than those in other countries who participated in the first phase of the project. UK institutions are also more likely to have a copyright policy and an individual with responsibility for copyright. The results should be of interest to library managers, library educators and those with responsibility for staff training.
\end{abstract}

\section{Introduction}

This article is based on a survey of UK library, information and cultural heritage sector professionals and their levels of knowledge about copyright issues. The data was collected in late 2014 following significant changes to UK copyright law, including several new exceptions of relevance to librarians and those working in the education and cultural sector. The survey instrument was developed in Bulgaria and findings from phase one of the project which surveyed

\section{Authors}

Chris Morrison is the Copyright and Licensing Compliance Officer at the University of Kent, responsible for copyright policy, training and advice. He was previously the Copyright Assurance Manager at the British Library.

Email: c.morrison@kent.ac.uk

Jane Secker is the Copyright and Digital Literacy Advisor at London School of Economics and Political Science where she coordinates digital literacy programmes for staff and students including copyright training and advice.

Email: j.secker@1se.ac.uk 
Bulgaria, France, Turkey and Croatia, were presented at the European Conference of Information Literacy in 2014 (Todorova et al., 2014). During the conference other countries were invited to participate in the survey and the UK was one of ten countries that took part in the second phase of the project.

The aims of the survey were:

- To investigate the level of copyright literacy amongst UK librarians and others working in the cultural heritage sector;

- To highlight any gaps in knowledge and training requirements in the sector;

- To provide data to compare copyright literacy levels in other countries participating in the survey.

At this stage analysis is being undertaken in other countries and so this paper focuses on the UK data. Where possible, comparisons are made with countries from the first phase of the project. The authors were particularly interested in ascertaining the levels of knowledge about copyright issues in the sector and attitudes towards copyright education, including professional qualifications in the library and related fields and continuing professional development (CPD). The article should be of particular interest to library managers, those developing and delivering CPD for librarians and those involved in the education of library and related professionals.

\subsection{Definitions}

Literacy is traditionally associated with the ability to read and write, but more broadly 'literacies' are cultural and communicative practices shared among members of particular groups. As society has evolved and technologies have developed we have seen a proliferation in the literacies that are required to live, learn and work. The term 'copyright literacy' was used by the originators of this survey and is part of a wider recognition that there are an increasing range of knowledge, skills and behaviours that individuals require when working with copyright content in the digital age. Copyright laws around the world are constantly trying to keep pace with the practices that digital technology now facilitates. Consequently, infringing copyright in a digital world is increasingly easy to do.

The study also attempts to place an understanding of copyright into a wider framework of digital and information literacy. Knowing how to use and share information and the ethical considerations are part of many major frameworks for digital and information literacy. The frameworks include the SCONUL 7 pillars, the ACRL framework and competency standards, Jisc's model of digital literacy and A New Curriculum for Information Literacy (ANCIL) (Secker and Coonan, 2012). ANCIL, for example, includes an entire strand on the ethical use of information, including an understanding of copyright. In February 2015, in an ACRL webinar, Smith and Cross (2015) explored whether copyright was the "third rail" (the controversial "charged" issue that people want to avoid touching) in information literacy, discussing how copyright issues can be introduced into information literacy teaching, and the difficulties and risks this presents. This 
webinar highlighted the concerns of librarians about giving what could be construed as legal advice.

\subsection{Why survey this sector}

Library and information science (LIS) professionals and those who work in related cultural heritage sectors such as museums, galleries and archives are increasingly grappling with copyright issues. This is particularly apparent with the shift towards delivering traditional services such as inter-library loan and core readings for students in digital format. As more resources are purchased in electronic format, so librarians need an understanding of licensing arrangements for these products. Many libraries and archives undertake projects to digitise their collections to both preserve them, and to open up access to the collection. In addition, librarians in higher education are often tasked with managing collective licensing on behalf of their organisation, for example coordinating the relevant Copyright Licensing Agency (CLA) Licence. This can lead to librarians being the first port of call for advice with copyright matters. In the earlier study carried out in France, Boustany (2014) argued that evidence from the survey would indicate the 'readiness' of the profession to deal with copyright issues raised by new technologies. In France where authors' rights are strong, Boustany argued there is an important need for librarians to develop 'copyright literacy' to redress the balance.

Professional qualifications in this sector have traditionally included an awareness of copyright law as part of the wider legal framework in which the organisations operate. Library staff are often 'at the coalface' when colleagues or library users want to copy and make use of printed and digital collections. In many instances users can now copy material using their own devices, such as tablets and smartphones, so it can be increasingly difficult to monitor copying within libraries. However, in museums, archives and special collections, staff may still have a greater element of control over how the material is handled and copied. Many professionals need to strike a balance between being seeing to 'police' copying and offering timely advice and support.

In higher education the reporting requirements of the CLA HE Licence for scanned readings means centralised services have been set up by many libraries to process and log digitisation requests for teaching. Some librarians and e-learning staff are taking on a policing role to ensure copyright material uploaded to the virtual learning environment (VLE) is compliant with the CLA Licence. Arguably, library staff need a greater level of understanding about the terms of this licence and any relevant copyright exceptions to oversee how copyright material is used in the VLE. These developments in collective licensing arguably mean that UK librarians need a more nuanced understanding of copyright in specialist situations than they did before the widespread adoption of digital learning tools.

\subsection{Background to the study}

This study originated from a project funded by the Bulgarian Ministry of Education and Science that surveyed information professionals in Bulgaria, Croatia and Turkey in 2013. In 2014 France joined the survey and high-level 
results from the first phase of the study were presented at the European Conference on Information Literacy (Todorova et al., 2014). The survey was repeated in late 2014 in ten other countries (UK, Finland, Hungary, Italy, Lithuania, Mexico, Norway, Portugal, Romania and USA) and data will be forthcoming to enable further comparisons in 2016.

\section{Literature review}

Prior to the Bulgarian study there had been little previous research examining copyright knowledge either in the wider education community or in the library and information profession. A study of the copyright knowledge of academic librarians was undertaken in Kenya (Olaka and Adkins, 2012). This study was prompted by the growing role for librarians to educate library users about copyright issues in light of increasing infringement. A study of archivists' knowledge of copyright was carried out in Canada (Dryden, 2012). Meanwhile another study explored the copyright knowledge of academic staff in the health sciences (Smith et al., 2006) and as far back as 2006, Danes (2006) suggested there was a 'copyright gap' in the education of new library professionals.

In the UK, a survey by Oppenheim and Woodward (2004) is perhaps of greatest relevance, for it investigated copyright advice and guidance services offered by UK libraries. The survey had 47 respondents and focused mainly on the academic library sector. It was distributed solely to members of a closed mailing list and gathered data on the respondents' gender, qualifications and job titles. It investigated how they dealt with copyright enquiries, how they kept themselves up-to-date and how difficult they found the current copyright environment. The research had some overlaps with our study, in that it examined issues associated with CPD. The survey was also conducted shortly after changes to copyright law in the UK.

The Oppenheim survey examined the levels of confidence amongst librarians when answering copyright queries. It found that respondents were generally fairly confident in handling queries, and they often had back up in the form of colleagues, lawyers or external staff. Many of the librarians were giving advice to people within their organisation, not just to library users, and more than half of their respondents ran training internally. What was clear was that copyright formed a small part of many librarians' roles, and understanding and managing licensing schemes such as that offered by the CLA contributed significantly to their work. Perhaps unsurprisingly, the mailing list where the survey was distributed rated highly as a way of keeping up-to-date, but training offered by individuals and professional associations was considered important for CPD. The survey also explored the topics that people wanted to know more about and these included what they termed 'E-copyright issues', scanning and digitisation and ejournal licences.

Another relevant study in the UK higher education sector by the National Union of Students (NUS) and the Government's Intellectual Property Office (IPO) explored students' attitudes towards copyright and intellectual property (IP) (NUS, 2013). This research surveyed just over 2000 students in further and higher education and found that their understanding of copyright and IP was relatively 
limited. Interestingly, most students felt they did not know enough about IP for their future careers and many said IP education was not embedded in their course. Students believed that most IP education focused on plagiarism issues and while IP is covered by most law schools in the UK, it is often not taught in other disciplines where it might be beneficial (e.g. media studies, creative arts and engineering). The study also suggested that, like other aspects of digital and information literacy, many academics did not feel they had the expertise to teach in this subject area, and they would need to bring in a guest lecturer.

Our survey is therefore of great significance if (as suspected at the outset) the levels of copyright literacy are relatively high in the UK library sector. If so, this could provide opportunities for collaboration between information professionals and educators, in order to embed copyright and wider IP issues into course curricula at both the school, further and higher education levels.

\section{Methods adopted}

In order to allow cross-country comparisons the survey instrument was supplied by the Bulgarian research team and distributed in the UK with only minor amendments for example, to ensure UK terminology was used such as 'fair dealing' rather than 'fair use' and to give examples of relevant UK copyright organisations. The survey was made available online using the open source survey tool: LimeSurvey (https://www.limesurvey.org/en/) and consisted of 4 sections. It included closed, half-open (through applying a 5-degree Likert scale) and open questions.

The first part of the survey aimed to establish the knowledge and awareness of the respondents on issues of copyright. It then explored the attitude of the respondents towards the development and application of copyright policies in library and cultural institutions. Section three examined attitudes towards formal copyright education and CPD, for example in library, archival and cultural heritage professional qualifications. Finally, the survey gathered demographic information including the educational and professional experience of the respondents. The full survey is available in the Supplementary File.

The survey was open throughout December 2014 and promoted via email discussion lists and social media, such as Twitter and LinkedIn. The authors targeted both copyright specific email discussion lists such as the JiscMail list LIS-Copyseek and lists related to information literacy, such as LIS-Infoliteracy. It was sent to discussion lists for school, public and government librarians and promoted on the UK museums, archives and galleries copyright distribution list. Twitter proved to be an effective way to promote the survey across the sectors and the survey was re-tweeted by the Chartered Institute of Library and Information Professionals (CILIP). Further information about the survey's aims was made available online and participants were able to view all the survey questions in advance. The intention was that as many relevant professionals would complete the survey as possible, to collect data from the profession as a whole, and not just from those with specific responsibility for copyright. Multiple submissions from the same institution were therefore encouraged. 


\subsection{Limitations}

A number of limitations with the methods adopted were identified, for example the authors had limited scope to amend the wording of the survey, if they wished to allow comparisons to be made with the data collected by other countries. In a few instances UK-specific examples were included in the survey for clarification, but the survey was largely distributed in the original format. This meant that the number of open questions was more limited than the authors would have liked.

Participants were self-selecting and so the survey may have been completed by staff with a greater level of awareness or specific interest in copyright. One of the main ways of publicising the survey was using the JiscMail list LIS-copyseek so arguably these respondents have the greatest level of knowledge about copyright issues, therefore skewing the findings. In addition, some of the questions relied on respondents' self-reported level of knowledge of copyright issues, which could reveal more about confidence in this field, than actual knowledge. However, the survey did not collect data about how participants heard about the survey, so we do not know how many members of the LIS-copyseek community completed it.

The length of the survey was also considerable and there was a significant drop off as people progressed through the survey. Of the 613 who started the survey, only 417 answered every question. This means that each question had a different number of responses. In addition no questions were compulsory. For clarity, the total numbers of respondents for each question are included in any charts in our findings, and the figures are given as percentages. The exception to this is the comparison of responses to single questions by demographic group, where figures are provided as both numbers and percentages. As percentages have been rounded up they do occasionally equal more than 100 percent.

\section{Findings}

\subsection{Survey demographics}

Demographic data helps to provide a useful context for our findings, so while this was asked at the end of the survey, it seems useful to present this first in this article. Of those who completed this question $76 \%$ were female and $24 \%$ were male, which is not atypical given the professions being surveyed. The age breakdown is included in Figure 1.

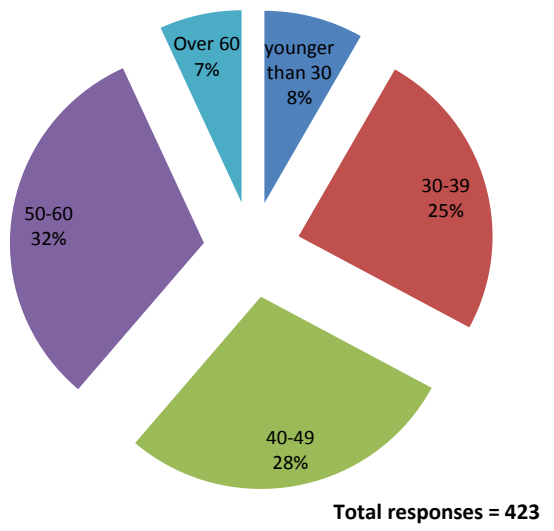

Figure 1: Age of respondents. 
The majority of our respondents $(63 \%)$ recorded their highest educational qualification as a Masters degree which is fairly unsurprising given the professions we were surveying. Fifty-two percent of respondents had a qualification in library or information studies and whilst our survey was promoted to those in museums, galleries and archives, the vast majority of the respondents were clearly librarians and many of those worked (57\%) in the academic library sector. The breakdown of respondents by sector is shown in Figure 2.

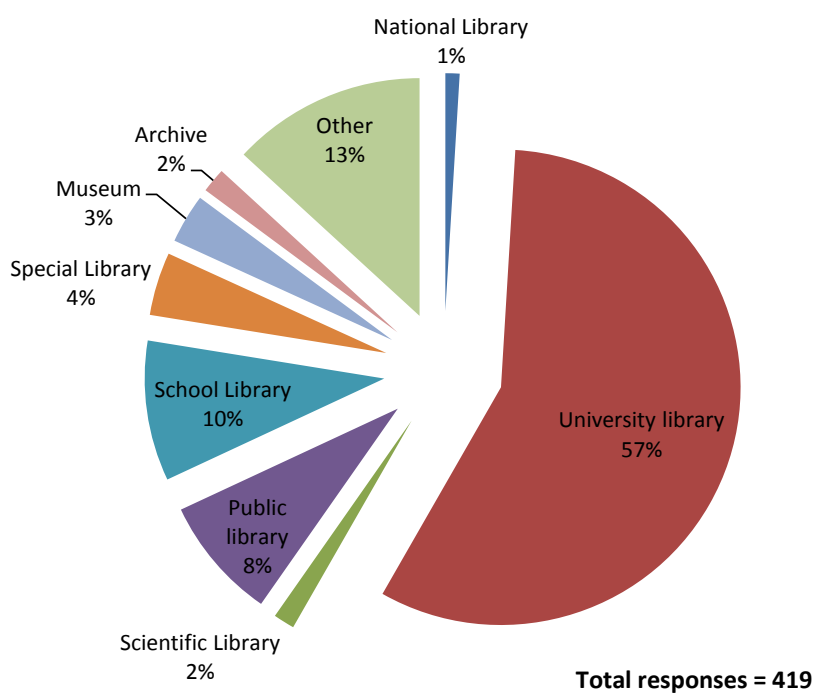

Figure 2: Respondents by sector / type of institution worked for.

Overall engagement with the survey was good, and the number of responses far exceeded the surveys conducted in Bulgaria, Croatia, Turkey or France. The high level of interest in the survey was indicated by over 100 respondents providing us with their email address and expressing a wish to be kept informed about the results.

\subsection{General knowledge and awareness of copyright}

The first section of the survey included ten questions to ascertain the general level of knowledge and awareness of a variety of copyright issues. Respondents were asked to comment on their overall familiarity with copyright and IPR issues. The survey used a five point Likert scale for these questions, which ranged from extremely aware, through to not aware at all.

Most respondents (40\%) described themselves as 'moderately aware' of copyright issues. Twenty seven percent were 'somewhat aware' while $17 \%$ said they were 'extremely aware'. Just 3\% of people were not aware at all of copyright and IPR issues (see Figure 3).

This data might suggest that our survey was completed by librarians and professionals in more generalist roles and not just the copyright officers within institutions. However, the nature of the survey means it reports on people's perception of their knowledge in the field. This point will be discussed further in Section 5, as clearly a copyright officer in an institution may still claim to be only moderately aware of the issues in the field depending on how they view themselves and their role. 


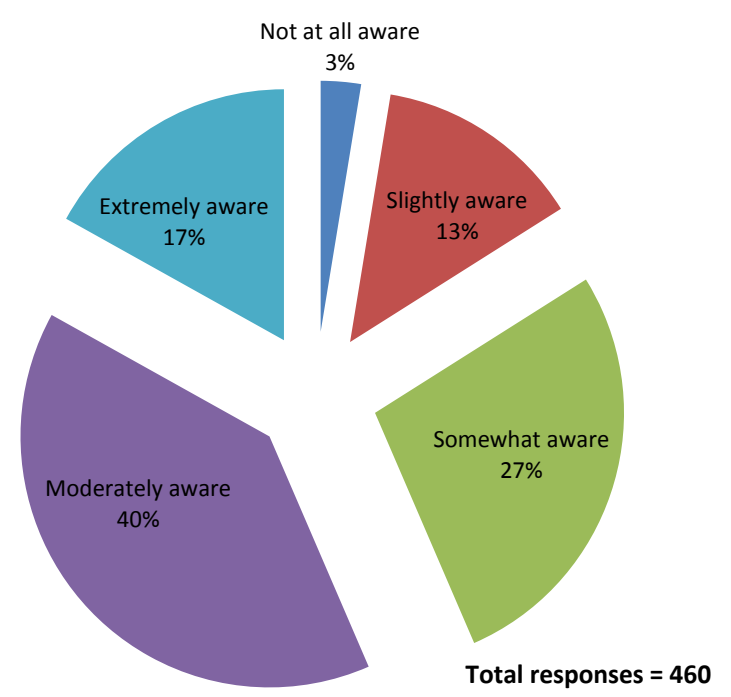

Figure 3: Levels of IPR / copyright awareness.

We further analysed the data to explore any differences in perceived levels of copyright literacy amongst the different sectors that completed the survey, while recognising that the greatest number of responses came from the academic library sector. Figure 4 illustrates how there is some variation in perceptions of knowledge depending on the sector. Levels of perceived copyright literacy appear to be lower in the public and school library sector and higher in the archive, museum, national library, special and academic library sector. However, some caution should be applied to this data given the lower number of responses from some sectors.

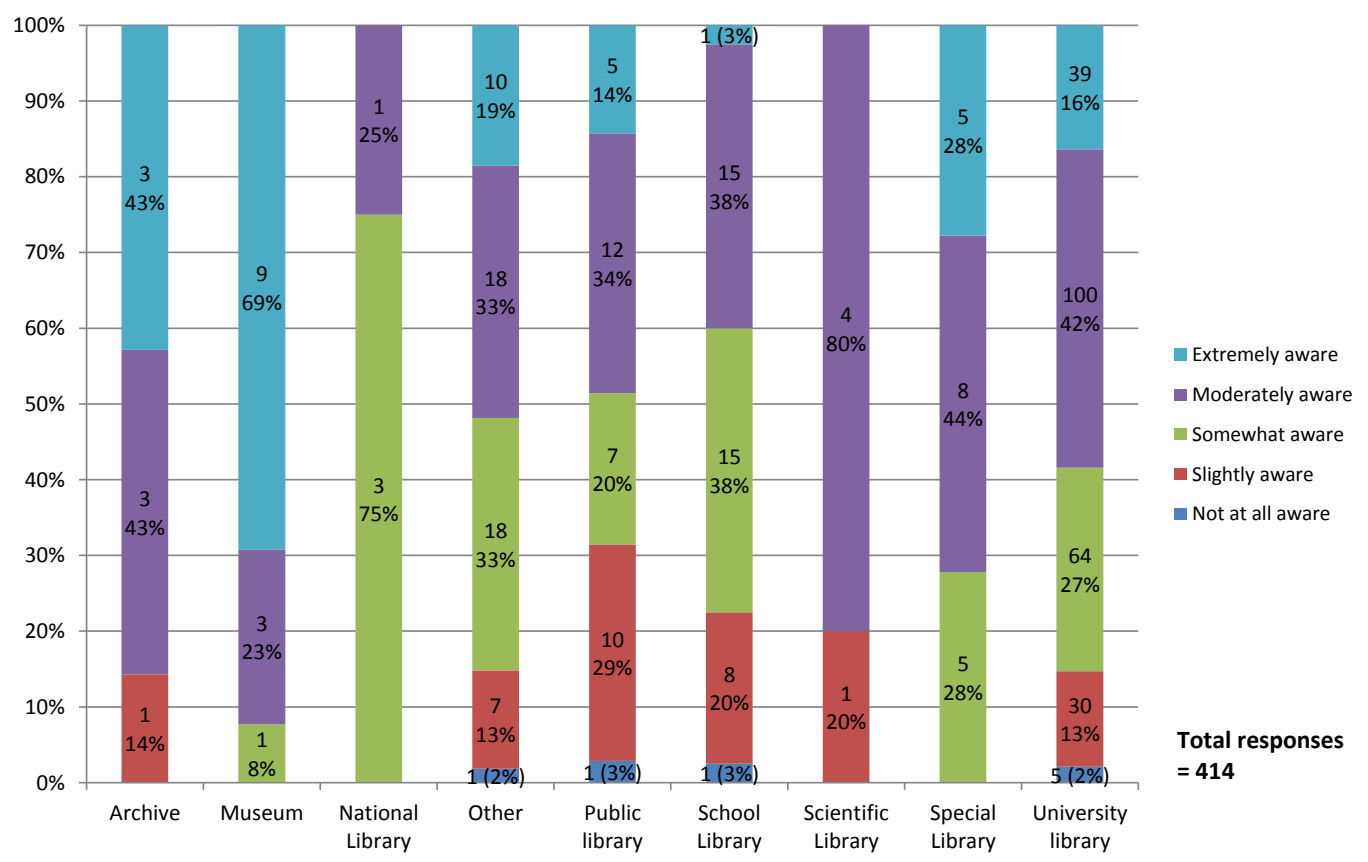

Figure 4: Analysis of intellectual property / copyright awareness perception by sector.

The levels of perceived copyright literacy were also compared by gender and age. The analysis of age did not appear to be statistically significant, with a relatively 
stable spread of confidence across the different age groups. The analysis of gender however did highlight some differences in perception with a larger proportion of males $(65 \%)$ identifying themselves as 'extremely' or 'moderately' aware of copyright compared to just $54 \%$ of females. Correspondingly, only $6 \%$ of males felt they were 'slightly' or 'not at all' aware of copyright compared to $19 \%$ of females. The authors carried out a Chi-square test to see if there is a correlation between gender and confidence in copyright literacy knowledge. The results $\left(\chi_{(4)}^{2}=9.66, p=0.047\right)$ show there is a statistical difference and that men report higher levels of confidence in copyright literacy than women. These findings have some parallels with studies of library and information students and the differing self-efficacy levels between men and women in information retrieval skills (Bronstein and Tzivian, 2013), however further research is recommended.

\subsection{Familiarity with the copyright framework}

Using the same five point scale, respondents were asked to indicate their perceived knowledge and awareness of the following issues:

- Copyright law at a national and international level;

- Copyright-related institutions at a national and international level;

- Collective rights organisations;

- Experience of clearing rights.

The findings suggest that knowledge of UK copyright law is an area where respondents had the greatest familiarity or confidence in their knowledge. Fiftyeight percent felt they were extremely or moderately familiar with UK copyright law. Meanwhile, $46 \%$ felt they were extremely or moderately familiar with UK copyright institutions. International copyright law and international copyright organisations were clearly the two areas where there was least perceived knowledge. There was also less experience of clearing rights amongst the respondents than might be expected. More than half of all respondents felt they were not at all, or only slightly familiar with this practice. Finally, knowledge of collective rights management (and organisations such as the CLA) was fairly evenly spread. Slightly more than half of all respondents felt they were not at all or only slightly aware of this, whilst $28 \%$ were extremely or moderately aware. Further details can be seen in Figure 5.

This section also asked respondents about their perceived knowledge of licences, copyright exceptions and related copyright issues. It asked about their familiarity with topics such as creative commons licences, fair dealing, open access, licences for electronic resources and issues related to e-learning. Licensing conditions in their own institution, licensing of digital resources, fair dealing and creative commons were all areas where many respondents reported being extremely or moderately aware. Open access was another issue that almost half (44\%) of respondents felt they were extremely or moderately aware. Copyright and elearning was an area where there was mixed levels of perceived knowledge: $34 \%$ of people believed they were moderately or extremely familiar with the issues, but $46 \%$ felt they were either not at all or only slightly aware. 


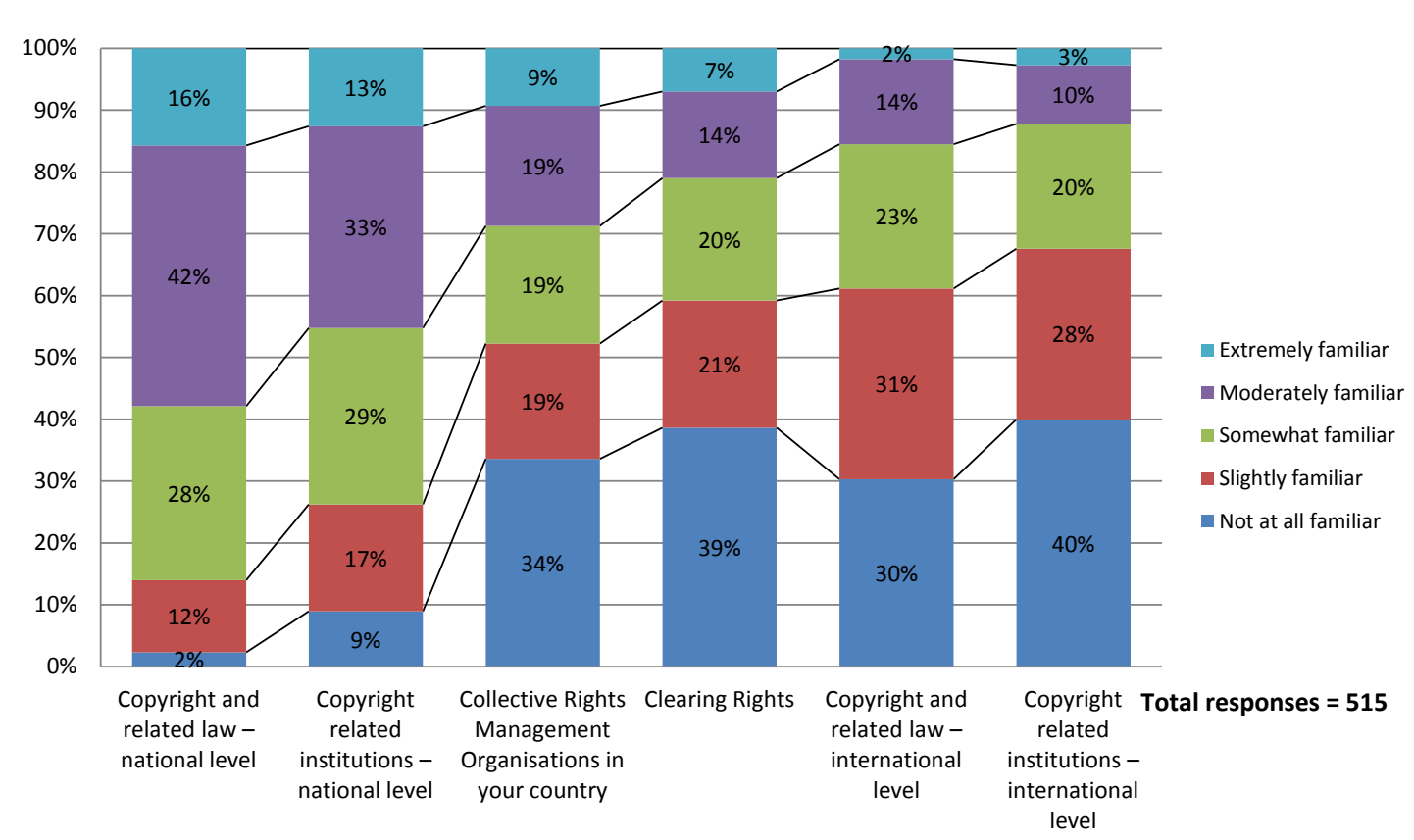

Figure 5: Familiarity with the copyright framework.

Copyleft was a term that over two thirds (67\%) of respondents were not familiar with although this may be a question of terminology rather than conceptual awareness. The term is more commonly associated with the open source software movement despite it being equivalent to the 'ShareAlike' component of the Creative Commons licences, with which $50 \%$ of respondents claimed to be extremely or moderately familiar. Further details are provided in Figure 6.

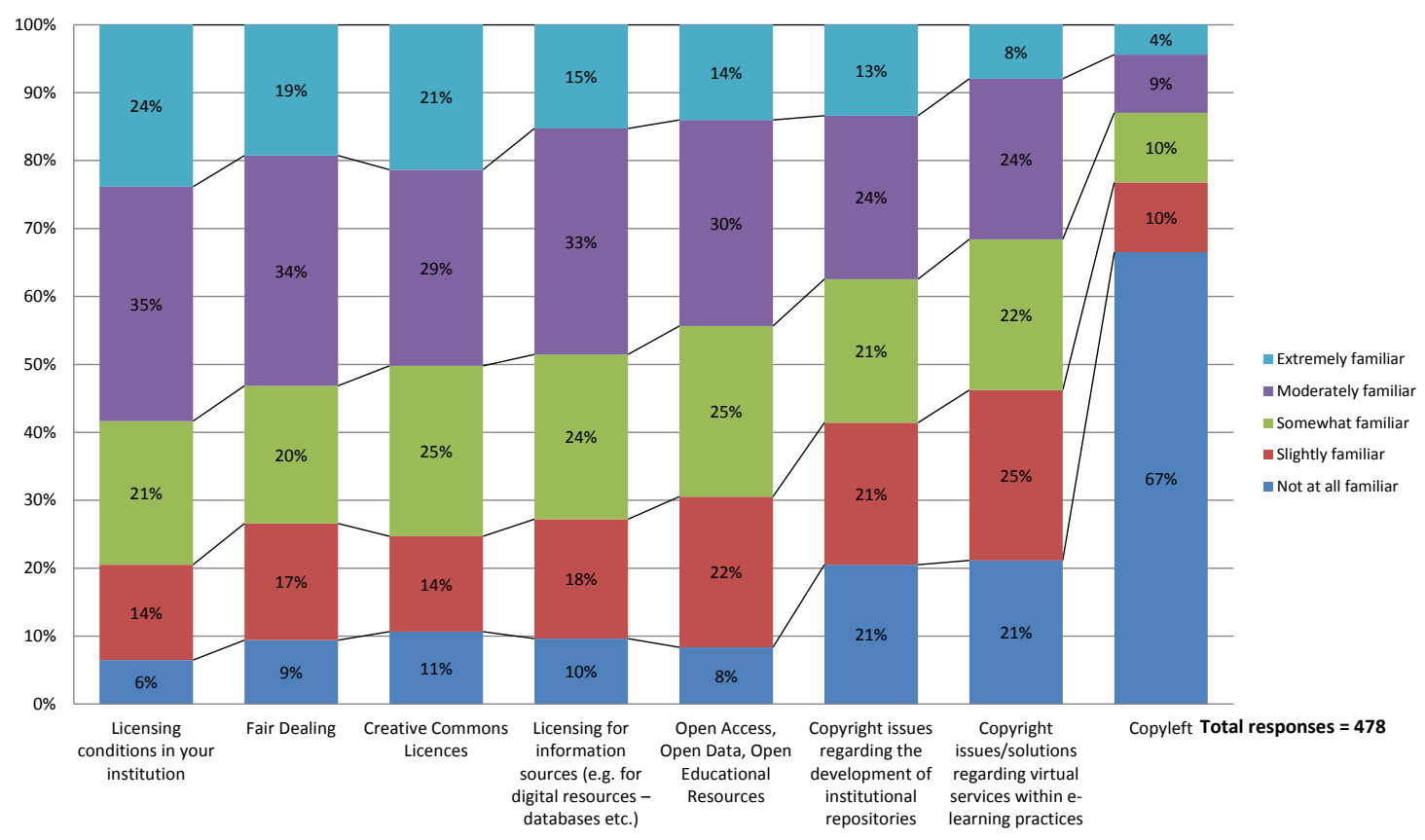

Figure 6: Familiarity with licences, exceptions and other issues.

The survey asked about familiarity with digitisation issues, out of print works, public domain materials and orphan works (see Figure 7). Digitisation was clearly an issue where almost half (49\%) of respondents felt they were extremely or 
moderately aware. Levels of awareness of out of print works, dealing with public domain materials and orphan works split the respondents almost equally. These topics appear to be ones where some members of the profession feel they have a greater level of expertise than others and this is likely to be related to their specific role and the nature of the organisations in which they work. For example, an archivist may be more familiar with public domain or orphan works issues than an academic librarian providing CLA-licensed scans.

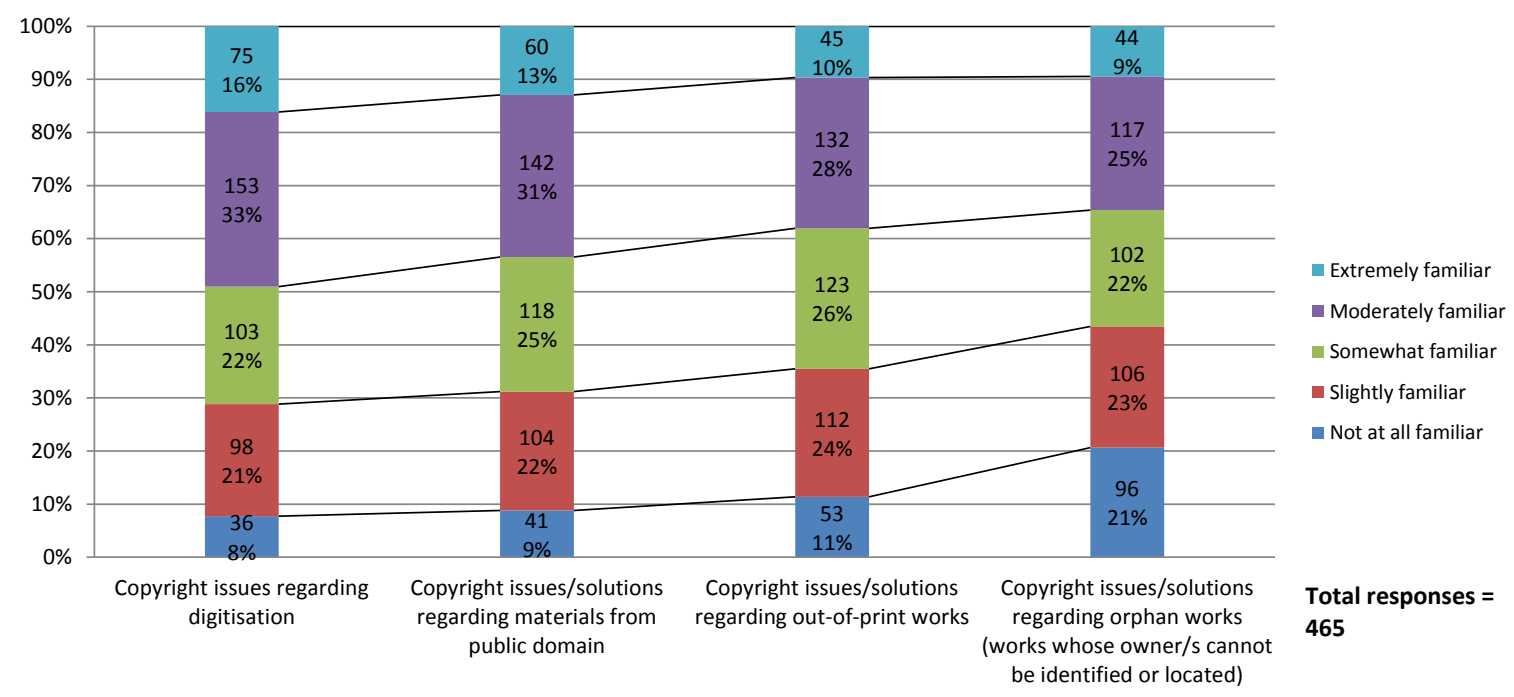

Figure 7: Familiarity with digitisation-related copyright issues.

The survey also asked how respondents kept up-to-date with copyright and IP issues in the context of their work. Figure 8 shows that websites (cited by $76 \%$ of respondents) and colleagues (70\%) are by far the most frequently cited sources of information. Books are also an important source of copyright information (cited by $62 \%$ of people), as are professional bodies (59\%) and email discussion lists such as the UK JiscMail list, LIS-copyseek (47\%).

Unfortunately, this part of the survey did not allow for free text comments to understand the types of websites that people used for copyright information. For example, it would be useful to know if the UK Intellectual Property Office (IPO) website was an important source of information. It is also interesting to note that lawyers were relatively low down on the list of sources (at 10\%) suggesting there is a benefit to having copyright advice available at a point of need and at a low cost.

Respondents were asked about their levels of interest in copyright initiatives from national libraries or from professional associations such as CILIP (the Chartered Institute of Library and Information Professionals) or LACA (the Libraries and Archives Copyright Alliance). The results suggest that most people (56\%) were moderately or somewhat interested in these initiatives, however only $19 \%$ said they were extremely interested. 


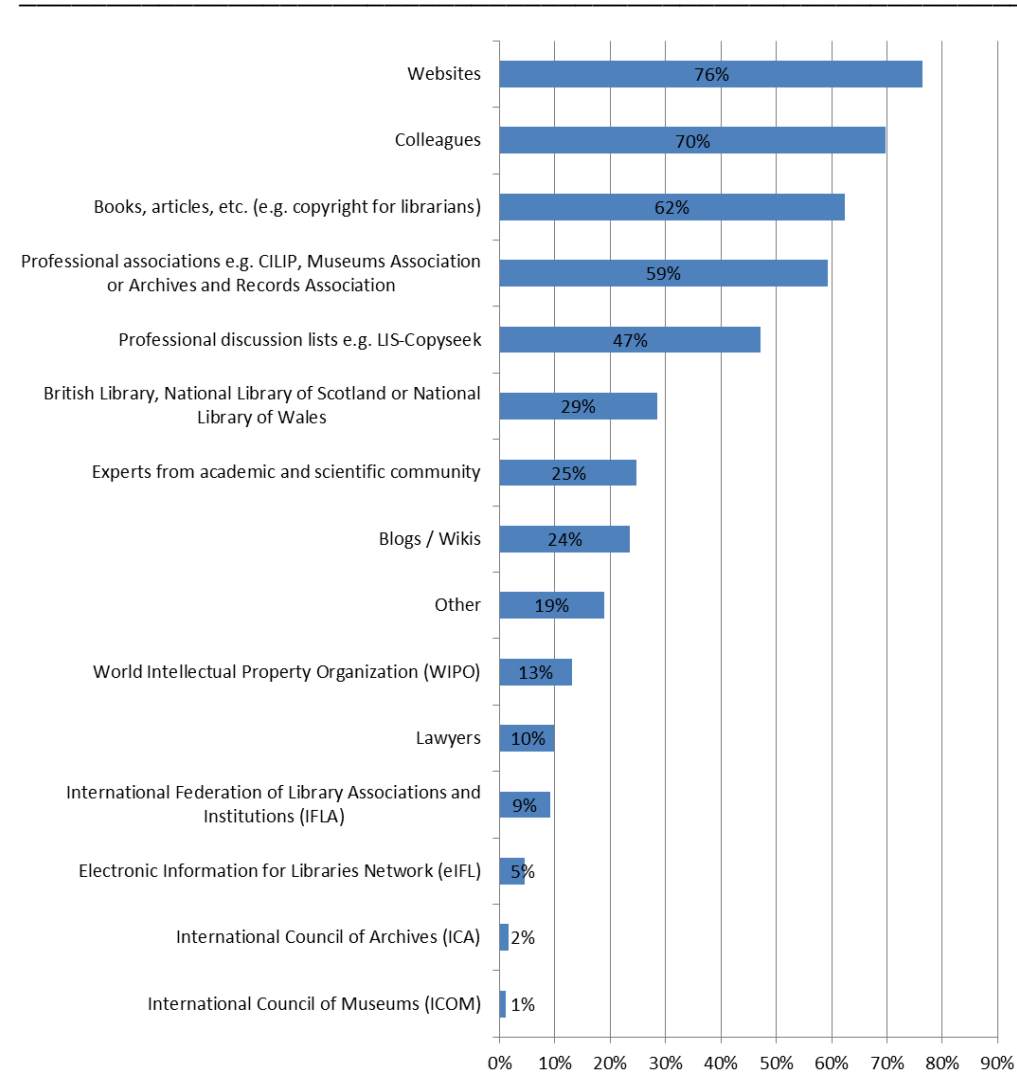

Figure 8: Sources of information for advice on copyright / IPR issues.

The next part of the survey tested people's understanding of UK copyright law at a deeper level. For example, respondents were asked if there was a national strategy for copyright in the UK. The results reveal a level of uncertainty in this area with $49 \%$ of people not knowing if such a strategy existed. This section also tested their understanding of UK copyright legislation, asking whether it included:

- A duration of copyright protection;

- Exceptions for private use, educational, scientific and research purposes;

- Exceptions for libraries, educational institutions, museums and archives;

- Rights for librarians to provide modified copies of works to serve the needs of visual impaired patrons;

- Provision for orphan works (e.g. compulsory license or limitation of liability).

Figure 9 shows that people had the greatest knowledge about the law making a provision for duration of copyright.However, knowledge of recent legislative changesuch as the UK's Orphan Works Licensing Scheme (launched by the IPO in October 2014) had clearly not reached all librarians and information professionals, as only $62 \%$ knew these existed.

In addition, levels of awareness of international copyright initiatives, for example the work of IFLA, are clearly less widely known in the UK with only $25 \%$ of people being aware of this work. 


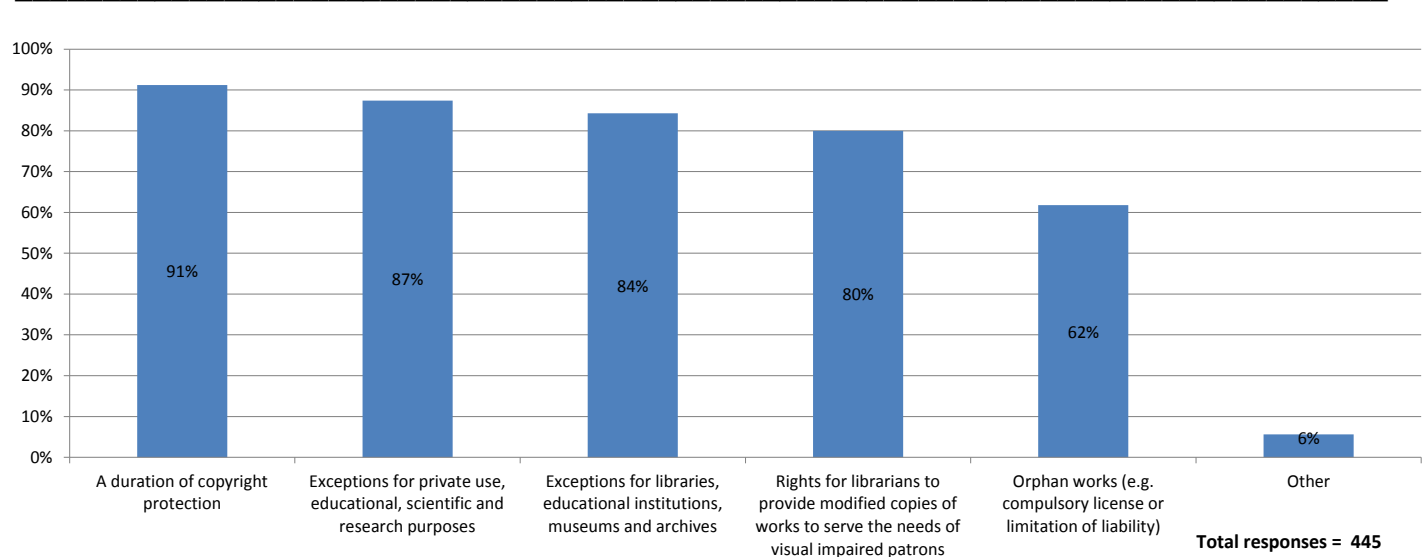

\section{Figure 9: Knowledge of UK copyright legislation.}

The final question in this section asked people whether they agreed with the following four statements related to copyright reforms:

- Services offered by libraries and other cultural heritage institutions require compliance with the copyright legislation;

- The World Intellectual Property Organization (WIPO) Treaty to Facilitate Access to Published Works for Persons who are Blind, Visually Impaired, or otherwise Print Disabled is an important achievement;

- WIPO should define better exceptions and limitations to copyright in the digital environment;

- Worldwide harmonisation of exceptions and limitations to copyright for libraries and archives is necessary.

There was a broad consensus from the respondents on the first two statements, with $91 \%$ and $87 \%$ of people agreeing. The majority of respondents also agreed with the final two statements, but to a lesser extent (Figure 10).

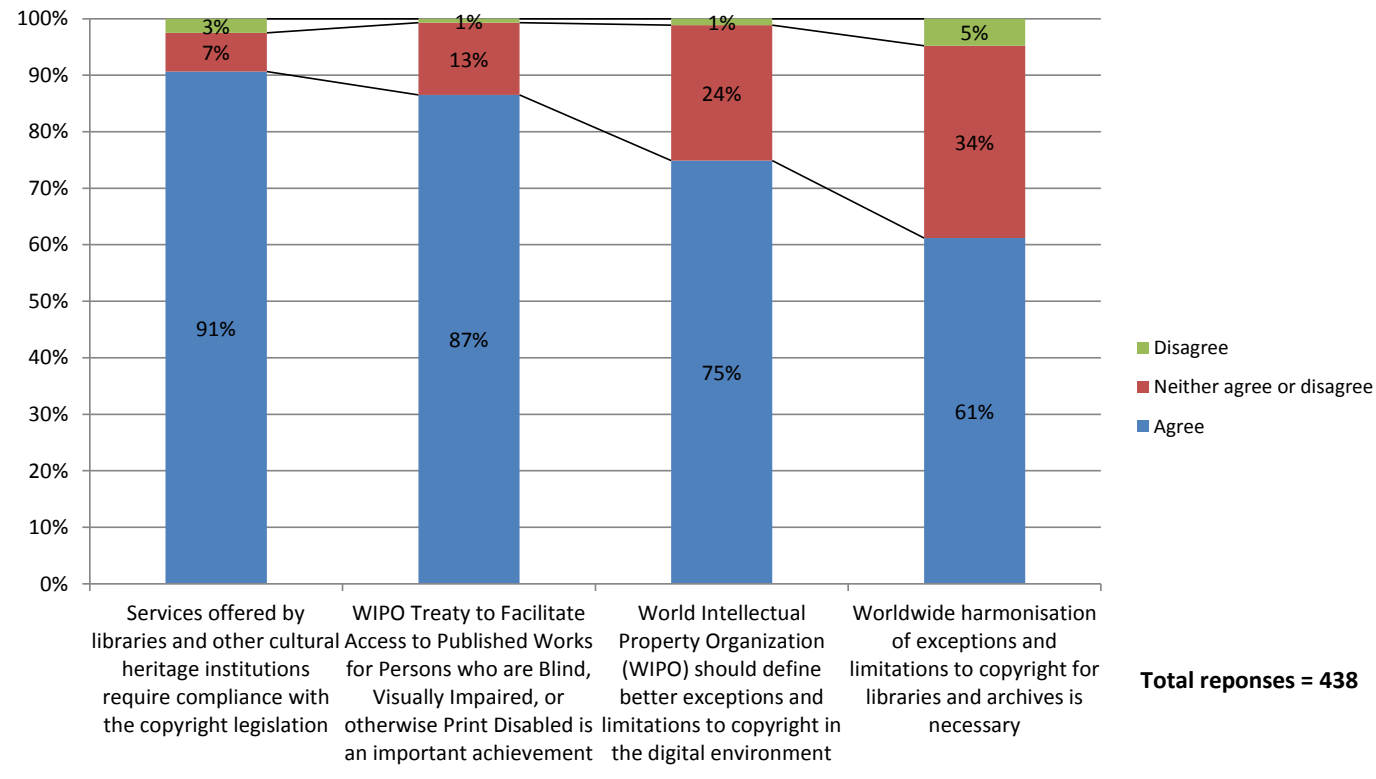

Figure 10: Opinion on statements about copyright reform. 


\subsection{Copyright policy at an institutional level}

The survey explored copyright issues and policies at an institutional level, investigating whether the institution owned resources protected by copyright, if respondents believed libraries and cultural institutions should have a copyright policy, whether there was someone responsible for copyright issues in their institution and whether the institution had a copyright policy. Figure 11 shows the findings in more detail. A slightly worrying point to note is that $10 \%$ of respondents did not believe their services required compliance with copyright legislation. The authors would like to explore this data in follow-up interviews and see if this perception was from individuals working at certain types of libraries or organisations.

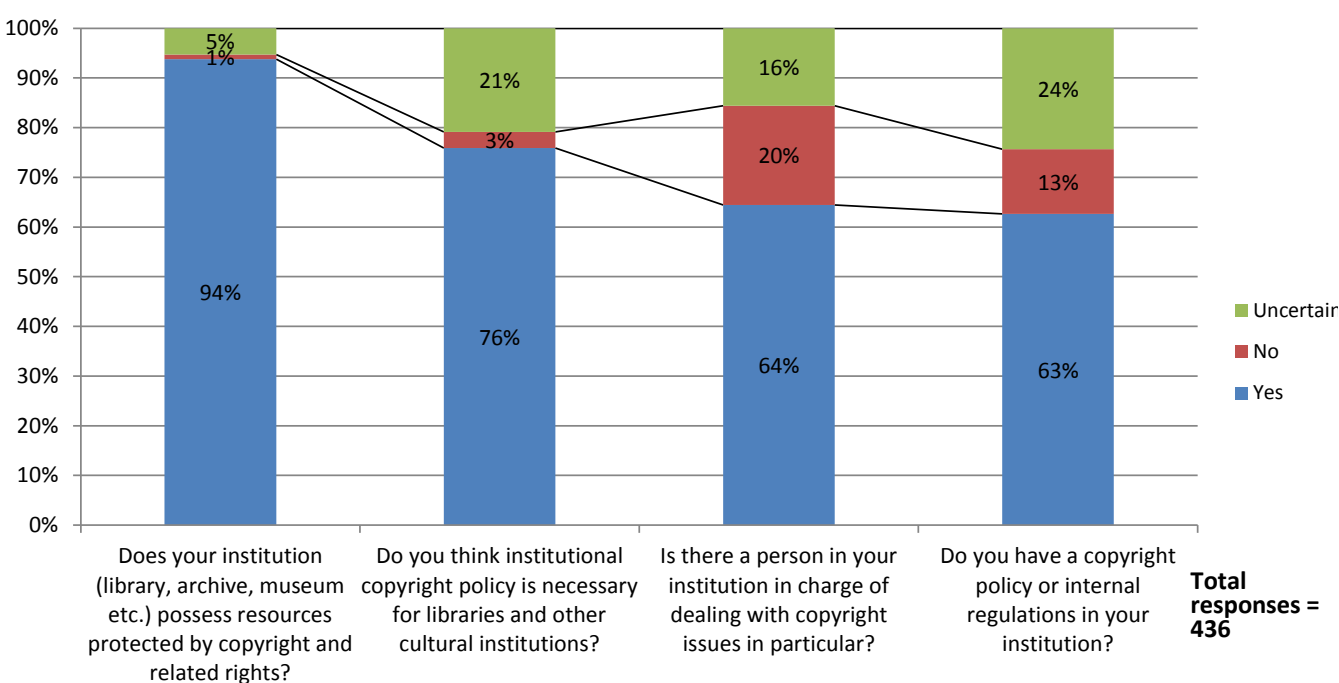

Figure 11: Copyright policy at an institutional level.

Unsurprisingly, almost all respondents (94\%) agreed that their institutions owned resources protected by copyright and related rights. The majority of respondents $(76 \%)$ thought that institutional copyright policies are necessary for libraries and other cultural institutions, although $21 \%$ of people stated they were uncertain about the need for such policies. Again, due to the wording of the survey it is not clear if these individuals were not sure what a copyright policy is or whether one was necessary. The survey went on to ask if the institution actually had a copyright policy or internal regulations. Sixty-three percent said they did, but again interestingly nearly a quarter of those who answered (24\%) the question were not sure if their institution had a copyright policy. The wording of this question was ambiguous so one explanation for this data might be that an employer may well have a copyright or IPR policy relating to whether the employer owns the copyright in materials made by staff in the course of their employment and/or a policy on employees' use of third party copyright materials.

Sixty-four percent of respondents stated that they had a person in their organisation responsible for copyright issues, which seemed relatively high. This question was of some interest to the researchers, both of whom deal with copyright issues in their own institution. The results found that $20 \%$ said there was not a person dealing with copyright and $16 \%$ did not know. Further analysis 
was undertaken to explore if the existence of a person responsible for copyright differed across the sectors. Figure 12 shows there are some differences with school and public libraries being far less likely to have someone in this role than a university or national library.

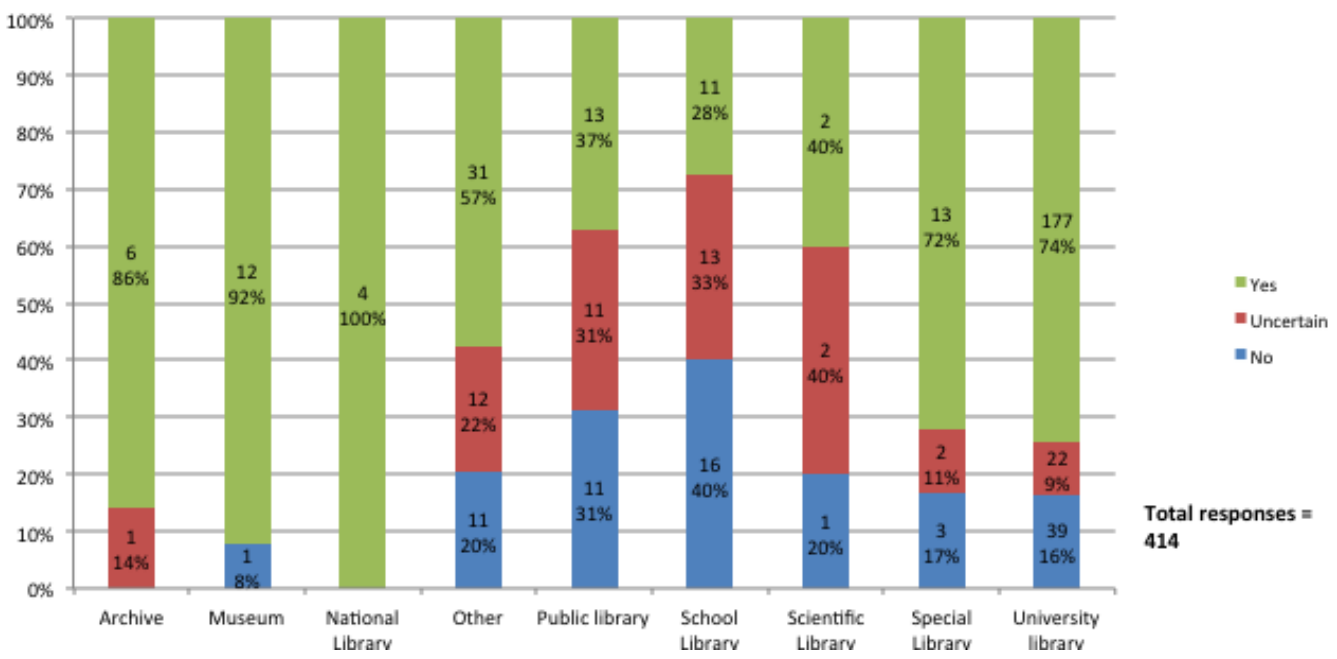

Figure 12: Persons responsible for copyright issues across the sectors.

A comparison was also undertaken across the sectors to see if the institutions have a copyright policy. Figure 13 shows that there are some differences with schools and public libraries slightly less likely to have a copyright policy than other sectors. However, $41 \%$ of public libraries and $53 \%$ of school libraries have a copyright policy or internal regulations, compared to $63 \%$ across the population as a whole. This discrepancy is because some sectors, such as university libraries, special libraries, national libraries and museums are far more likely to have a copyright policy. For example, in university libraries, the sector with the largest number of respondents (238) 64\% have a copyright policy.

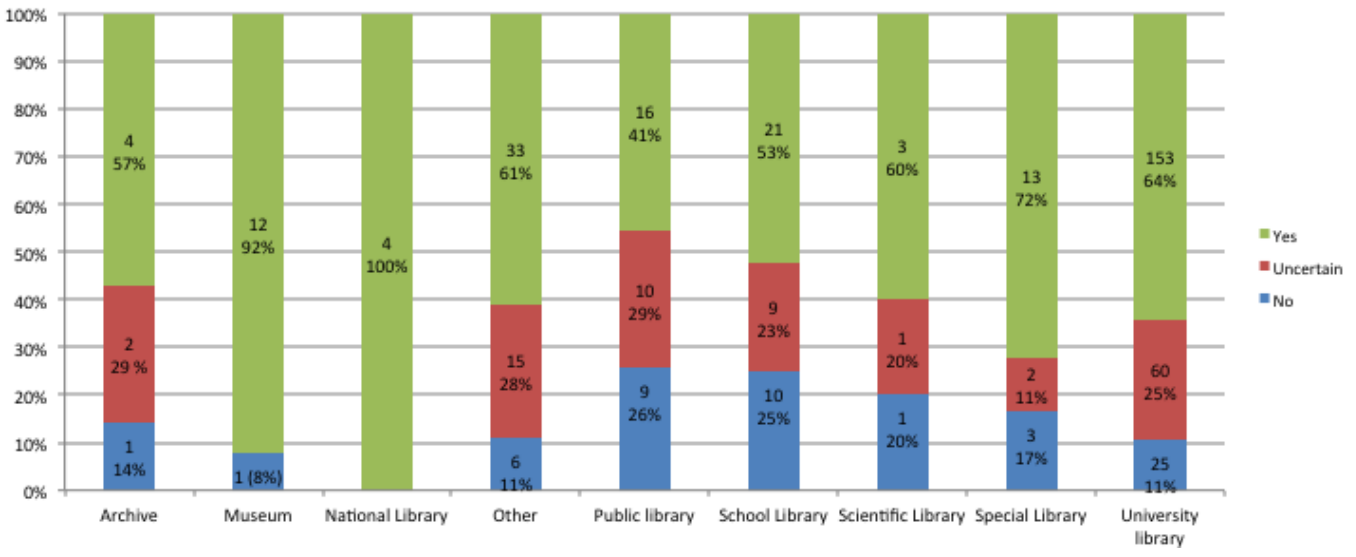

Figure 13: Copyright policy or internal regulations by sector.

\subsection{Copyright and education}

The final section of the survey asked respondents about the need for copyright and IPR to be included in formal education and CPD. In this section, the survey included open-ended questions to allow respondents to describe in more detail the topics they thought should be covered. The results were illuminating. 
In both the case of formal education (such as LIS or archive administration masters courses) and CPD the majority of respondents (over 90\%) believed that copyright and wider IPR issues should be included in the curriculum (see Figure 14).

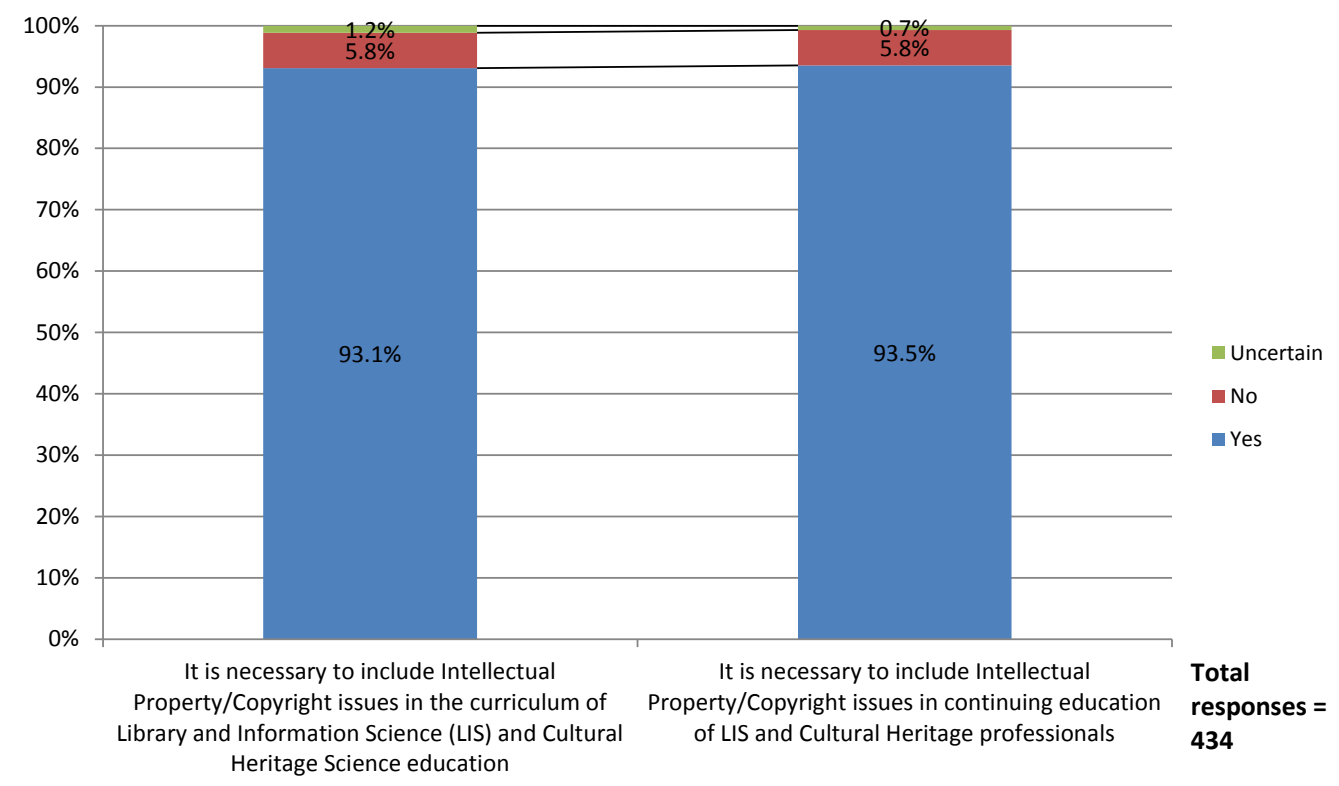

Figure 14: Opinions on inclusion of IPR issues in LIS Education.

The survey asked which topics should be included in formal education and in CPD for librarians and related professionals. The qualitative data was analysed and categorised into over fifty unique topic categories, all of which were mentioned by at least one respondent. In terms of formal education, the most frequently cited topics are listed in Table 1. Fairly unsurprisingly, an overview of UK copyright law was suggested most frequently, followed closely by an understanding of copyright exceptions and how these relate to the licences an organisation might have. Many respondents wanted the focus of education programmes to be on understanding the law in practice. Digital copyright was also an important topic, as well as Creative Commons.

The free text comments included in this part of the survey were also particularly interesting and a selection are included below. Many respondents expressed the need to understand about a wide variety of topics related to copyright and IP and to have them explained clearly and in an engaging way. As one respondent said:

General copyright awareness / copyright duration / using images / fair dealing and quotation / digital content rights / creative commons / understanding terms \& conditions \& re-use licenses / implications of non-compliance (but in a good way using carrot not stick). Whatever it is it needs to be clear and as jargon free as possible to stop people glazing over.

Another stated copyright education should:

... reflect the fact that most LIS practitioners have significant exemptions and freedoms as regards copyright. Much existing copyright education is effectively written from a commercial rights holder perspective and tends to be unduly dogmatic as a result. 


\begin{tabular}{|c|c|}
\hline Topic & $\begin{array}{l}\text { Number } \\
\text { of } \\
\text { responses }\end{array}$ \\
\hline Overview of UK copyright legislation & 68 \\
\hline Copyright exceptions / relation to licences & 43 \\
\hline Practical application of copyright law & 34 \\
\hline Digital copyright / copyright and the internet & 33 \\
\hline Creative Commons / copyleft & 31 \\
\hline Fair dealing & 27 \\
\hline Specific Licensing schemes e.g. CLA, ERA & 27 \\
\hline Exceptions for libraries & 24 \\
\hline Open access and institutional repositories & 23 \\
\hline $\begin{array}{l}\text { Copyright of specific types of works e.g. images, music, unpublished } \\
\text { works }\end{array}$ & 21 \\
\hline International copyright law & 20 \\
\hline Licensing of digital resources & 20 \\
\hline Copyright duration / out of copyright work & 20 \\
\hline Copyright and digitisation / preservation & 18 \\
\hline Exceptions for educational use & 17 \\
\hline How to protect IP & 16 \\
\hline Knowing how to stay up-to-date / good sources of copyright info & 15 \\
\hline Clearing rights / tracing rights holders & 14 \\
\hline What copyright covers / limitations & 13 \\
\hline $\begin{array}{l}\text { Copyright issues affecting particular user groups e.g. academics, } \\
\text { students, members of the public, commercial uses, NHS }\end{array}$ & 13 \\
\hline
\end{tabular}

\section{Table 1: Topics for inclusion in the formal education of LIS and cultural heritage sector professionals.}

Another recognised the apprehension, and anxiety that some professionals have about copyright issues, stating:

I think it would be helpful to provide an overall view of copyright and how it might impact on people. I think copyright can seem daunting if you are not familiar with it, and by encouraging an awareness at an early stage, this would reduce any anxieties to follow.

Another respondent agreed with this point stating:

I find that people are often scared of copyright, or uncertain, so a good solid grounding on your own country's copyright laws and exceptions would be good. 
This respondent was critical of his/her recent qualification, stating:

I have just finished my MSc and we had limited information on copyright law provided, the little I know I know because colleagues have shared it with me.

Another respondent echoed this point saying:

I believe that this subject area should be dealt with in as practical a way as possible. What kind of issues are likely to face librarians in their day-to-day work? What are they allowed to do and for whom? I don't remember copyright issues being addressed at all in my Postgraduate course and I think this was unfortunate.

However, respondents were aware that copyright education was challenging to teach and three respondents suggested it should be embedded into different modules, rather than delivered as a standalone topic. Several interesting topics were not listed in Table 1 because they were only mentioned by between 5 and 10 respondents, although they are worthy of note. For example, eight respondents thought information about the ethics and philosophy underpinning copyright should be covered in professional qualifications and other respondents felt there was a need to understand some of the main differences between copyright laws in countries outside the UK.

The second question in this section asked participants to specify the topics / issues they thoughts should be covered in a CPD programme. Many of the same topics were mentioned and Table 2 shows the most frequently cited topics.

Slightly fewer respondents answered the above question and several people said that all the same topics they mentioned in their previous answer should be included in CPD. However, there are some key differences. An understanding of recent updates to the law was the most frequently cited topic. However, many people wanted knowledge of practical aspects of copyright related to their job and how to deal with common copyright queries. Again quotes from this section of the survey are included. The need to keep up-to-date with recent changes in the law, caused in part by technology was a concern expressed by many respondents, as one said:

...I still need to know what I am allowed to do and for whom, especially as digitisation has changed the field completely. We need updates on how legislation has changed and what a difference this makes to our work.

Another interesting aspect, mentioned in the survey by 10 people, was their role in providing copyright training and education for others in their organisation. One respondent said they wanted to know:

...how to advise people on copyright issues, copyright legislation and its impact in the academic environment, how to help creators protect their copyrighted works.

Another said:

Encouraging more general awareness of copyright issues so librarians/info specialists can educate academics about complying with copyright law. Also practical awareness for students' creative work and using [copyright] material in their own work. 


\begin{tabular}{|l|l|}
\hline Topic & $\begin{array}{l}\text { Number } \\
\text { of } \\
\text { responses }\end{array}$ \\
\hline Recent updates to the law & 67 \\
\hline Overview of UK copyright legislation & 48 \\
\hline As per previous answer & 41 \\
\hline Practical application of copyright law & 30 \\
\hline Copyright exceptions / relation to licences & 23 \\
\hline Digital copyright / copyright and the internet & 20 \\
\hline How to protect IP & 17 \\
\hline Fair dealing & 16 \\
\hline Exceptions for libraries & 15 \\
\hline Open access and institutional repositories & 15 \\
\hline Creative Commons / copyleft & 15 \\
\hline Specific Licensing schemes e.g. CLA, ERA & 15 \\
\hline International copyright law & 14 \\
\hline Licensing of digital resources & 13 \\
\hline $\begin{array}{l}\text { Copyright issues affecting particular user groups e.g. academics, } \\
\text { students, members of the public, commercial uses, NHS }\end{array}$ & 13 \\
\hline Case studies of impact on libraries and LIS bodies & 13 \\
\hline What copyright covers / limitations & 12 \\
\hline Orphan works & 10 \\
\hline Copyright training / education for others & 10 \\
\hline $\begin{array}{l}\text { Copyright of specific types of works e.g. images, music, unpublished } \\
\text { works }\end{array}$ & 9 \\
\hline Copyright and digitisation / preservation & 9 \\
\hline Table $:$ Topics for inclus in the continuing professomal deveropment \\
\hline
\end{tabular}

\section{Table 2: Topics for inclusion in the continuing professional development of LIS and cultural heritage sector professionals.}

Keeping up-to-date in the field was clearly important to many, as this respondent said:

Summarize copyright laws as they apply to educational institutions. Provide suggestions of good websites/resources for keeping up-to-date with copyright law.

The survey asked for respondents' preferences for receiving CPD in this field. Training courses were the most popular (cited by $85 \%$ of people), with online resources from websites as being the next popular (cited by $82 \%$ of people). Distance learning or e-learning was another popular choice (80\%).Figure 15 
provides further details but the results are fairly unsurprising and reflect the preference for face-to-face training followed by online resources and online courses.

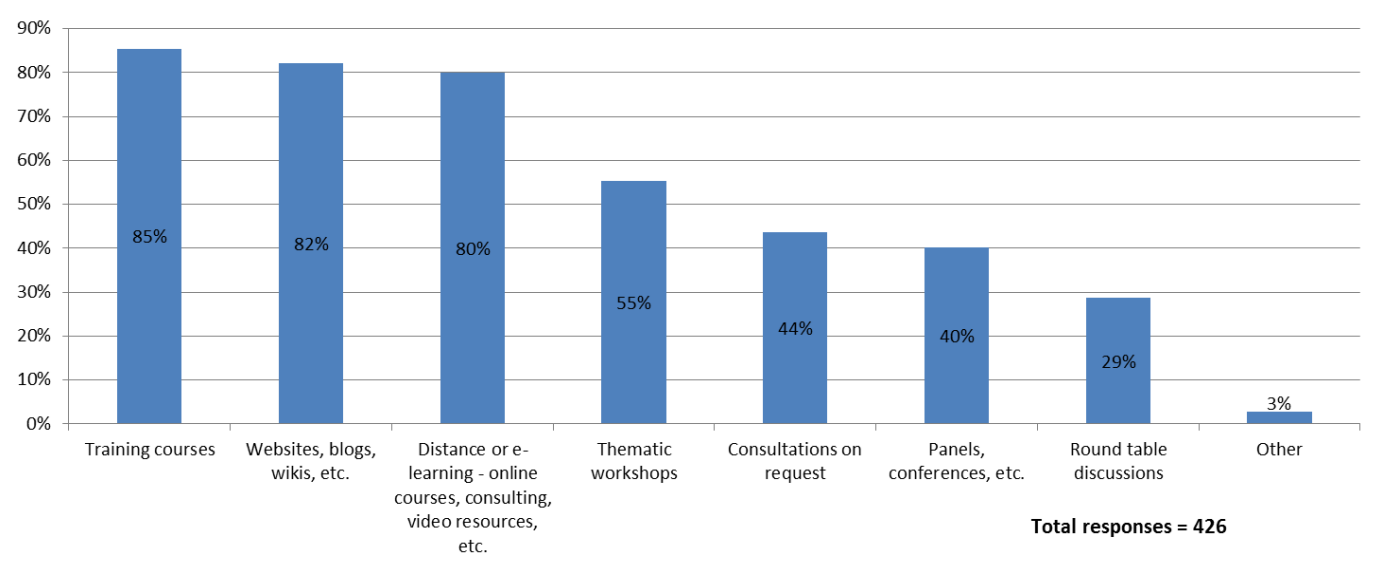

Figure 15: Preference for the delivery of copyright education.

\section{Discussion}

The data collected in this survey provide the first large-scale copyright awareness UK study of LIS and related professionals. It suggests that levels of copyright literacy amongst this group are high, in particular when compared to other countries. The survey was not without limitations in that it asked mainly closed questions. It may also be skewed somewhat as the highest number of respondents came from the academic library sector. Comparing the levels of confidence in copyright issues between the sectors suggests that public and school librarians are less confident. Similarly their institutions are less likely to have an individual with specific responsibility for copyright matters or copyright policy.

The closed nature of many of the questions makes some of the data more difficult to interpret, as there are several places where clarification or a free text answer might have illuminated an issue. For example, the survey asked about familiarity with "copyright issues associated with digitisation" but although $49 \%$ of people reported being familiar, the term digitisation has several meanings. Those working in a museum, archives or special collections role might interpret this to mean digitising collections, for preservation or to improve access. However, the term is also used to mean the digitisation of core readings which many university libraries now do routinely under the CLA Licence. Usually when digitising a collection you would need some experience of clearing rights, however the data presented in Figure 5 showed only $21 \%$ of respondents were extremely or moderately experienced in clearing rights. This suggests that this question could have been interpreted differently by those in different sectors.

The findings suggest that in the UK there is a recognised need for copyright expertise within an organisation, although it is not always the case that a dedicated post exists. Respondents expressed a desire to learn more about copyright in their professional qualifications and also to be kept up-to-date on issues relating to their job. The quotes from the participants about copyright education suggest many professionals feel they still do not know enough about copyright, and have some 
level of anxiety over dealing with copyright queries. There are also clear preferences for the delivery of copyright education and training. There were a number of questions where people chose not to answer or were uncertain, suggesting that copyright terminology could be off-putting or confusing. The data also suggests that while many UK professionals are reasonably confident about their knowledge of UK copyright law, international issues and recent changes to the law have heightened awareness about the need to keep up-to-date.

As this study was part of a larger international study, and the data analysis is still on-going in nine countries, it was only possible to undertake a limited crosscountry comparison. Comparing the UK data to the findings from the first phase of the project (Todorova et al., 2014, 143) reveals interesting differences and in general levels of copyright literacy appear to be higher in the UK compared to Turkey, France, Bulgaria and Croatia. Fifty-seven percent of UK respondents are either extremely or moderately aware of copyright and IPR issues compared to just $32 \%$ across Bulgaria, Croatia, France and Turkey. There are several other areas of interest where we can compare the data to the Todorova et al. $(2014,146)$ study. For example, in terms of copyright policies within institutions, the earlier study found that $76 \%$ of institutions believed they had resources protected by copyright, compared to $96 \%$ in the UK. Eighty-four percent of non-UK respondents thought institutions should have a copyright policy, yet only $34 \%$ actually had one. This compares to $63 \%$ of institutions in the UK having a copyright policy and $76 \%$ thinking they should have one. This suggests that the more widespread adoption of copyright policies in the UK may have led to a slightly higher level of ambivalence about their necessity. Finally, only $15 \%$ of institutions surveyed in Croatia, Bulgaria, Turkey and France had a person responsible for copyright whereas in the UK this figure was $64 \%$. The differences in the UK data are marked. The survey did not question respondents about the approach to risk management within their organisation, however the relatively high number of copyright officers in UK libraries and related organisations, suggest the UK takes copyright issues seriously and organisations may be relatively risk averse. Alternatively, the existence of dedicated copyright support staff might actually enable institutions to manage risk more effectively, therefore allowing them to be more innovative. Further research is recommended.

Unfortunately, there is not currently any comparative data from the earlier study to compare the topics that should be included in copyright education. However, the earlier study found $71 \%$ of respondents thought copyright and IP should be included in undergraduate curricula for LIS professionals with lesser numbers wanting it included in masters and PhD level education (Todorova et al., 2014, 146).

\section{Conclusion and recommendations}

Copyright literacy is clearly a growing requirement for staff working in the library and cultural heritage sectors and the findings from the UK study compare favourably to the earlier study of professionals in Bulgaria, Croatia, France and Turkey. However, further cross-country analysis with the countries who participated in the second phase of the study will prove invaluable. 
The findings suggest that copyright should be embedded into the formal education and CPD of library and related professionals. Copyright clearly causes anxieties amongst some library staff who see themselves as taking on a role akin to providing legal advice. However, by viewing copyright as a key part of digital and information literacy, where the librarian's role is to empower learners and researchers through developing skills and behaviours to aid decision making, confidence in teaching about copyright and answering queries may improve. Library educators and those in CPD need to think carefully about how best to teach others about copyright to ensure it is both engaging and relevant. Meanwhile, librarians with their high levels of copyright literacy are in a strong position to work to embed copyright into the curriculum of courses at all levels.

The researchers recommend that further research is undertaken to gather more qualitative data to deepen the level of understanding about copyright literacy in the sector. It would also be useful to repeat the survey with other groups of professionals to enable comparisons to be made with, for example, senior managers in higher education, academics, other groups of administrative / professional services staff, educational developers, or e-learning staff.

\section{References}

Boustany, J. (2014) Copyright Literacy of librarians in France [online].Paper presented at the European Conference of Information Literacy. Dubrovnik, Croatia, October 2014. URL: http://ecil2014.ilconf.org/wpcontent/uploads/2014/11/Boustany.pdf

Bronstein, J and Tzivian, L. (2013) Perceived self-efficacy of library and information science professionals regarding their information retrieval skills. Library and Information Science Research, 36(2), 151-158.

Danes, K. M. (2006) Library Schools and the Copyright Knowledge Gap, Information Today, 23(2), 1-15.

Dryden, J. (2010). What Canadian Archivists Know About Copyright and Where They Get Their Knowledge, Archivaria, (69), 77-116.

NUS (2013) Student attitudes towards intellectual property [online]. URL:http://www.nus.org.uk/PageFiles/12238/IP\%20report.pdf

Olaka, M. W. and Adkins, D. (2012) Exploring copyright knowledge in relation to experience and education level among academic librarians in Kenya, International Information and Library Review, 44(1), 40-51.

Oppenheim, C. and Woodward, I. (2004)A survey of copyright advice and guidance in UK higher education libraries, Library and Information Research [online], 28 (89).

URL:http://www.lirgjournal.org.uk/lir/ojs/index.php/lir/article/view/167/214

Secker, J. and Coonan, E. (2012) Rethinking Information Literacy: a practical framework for supporting learning. London: Facet Publishing. 
Smith, K. H., Tobia, R. C., Plutchak, T. S., Howell, L. M., Pfeiffer, S. J. and Fitts, M. S. (2006) Copyright Knowledge of Faculty at Two Academic Health Science Campuses: Results of a Survey. Serials Review, 32(2), 59-67.

Smith, K and Cross, W. (2015) Is Copyright the third rail in information literacy, or a common denominator? [online]. ACRL Webcast, 25 February 2015. URL: http://www.ala.org/acrl/intersectionswebcast

Todorova, T., Trencheva, T., Kurbanoğlu, S., Doğan, G., Horvat, A and Boustany, J. (2014) A Multinational Study on Copyright Literacy Levels of LIS Professionals [online]. Paper presented at the European Conference of Information Literacy. Dubrovnik, Croatia, October 2014. URL: http://ecil2014.ilconf.org/wp-content/uploads/2014/11/Todorova.pdf

\section{Acknowledgement}

The authors would like to acknowledge the assistance of Jose Pina-Sánchez, Lecturer in Quantitative Criminology at the University of Leeds for his help and advice over the performance of the Chi-sqaure statistical test.

\section{Open access and copyright}

Library and Information Research is an open access journal. A freely available copy of this paper may be downloaded from the journal's website:

http://www.lirgjournal.org.uk.

Copyright and associated moral rights in works published in Library and Information Research are retained by the author(s) but this paper may be used freely, with proper attribution, in educational and other non-commercial settings. 